\title{
PREPARATION AND EVALUATION OF ULTRASOUND TRANSMISSION GEL
}

\author{
AMINA M AL-NIMA ${ }^{1 *}$, MYASAR AL-KOTAJI ${ }^{1}$, OSAMAH AL-IRAQI'², ZAHRAA H ALI ${ }^{3}$ \\ ${ }^{1,3}$ Department of Pharmaceutics, College of Pharmacy, Mosul University, Mosul, Iraq. ${ }^{2}$ Department of Internal and Preventive Medicine, \\ College of Veterinary Medicine, University of Mosul, Mosul, Iraq. Email: am.mudhafar@gmail.com
}

Received: 10 October 2018, Revised and Accepted: 23 November 2018

ABSTRACT

Objective: Formulation of an alternative ultrasound transmission gel that is of good quality using the available chemicals in Iraqi market and without any harmful effects to skin.

Methods: Four formulas G1, G2, G3, and G4 with different Carbopol 934 concentrations $(0.3,0.4,0.5$, and 0.6) w/v\%, respectively, were prepared and evaluated for different physicochemical characteristics including: Clarity, homogeneity, density, pH, viscosity, and spreadability tests. Other evaluations including skin irritation, microbiological, and stability tests were also performed for the selected formula along with a comparison study with the commercially available ultrasound gel (commercial gel [CG]) which was used as a control. In addition, transmission test was carried out by comparing the transmission between (CG) and (G1) with the assistance of three veterinary radiologists who did ultrasonography of bovine liver for 11 adult cattle breed, aged 3-8 years. The three veterinary radiologists were given 33 data sheets to collect results.

Results: Among all the prepared formulas (G1), the formula was considered the best, due to its high clarity, very good homogeneity; its $\mathrm{pH}$ was equal to 6.8 which is near to skin $\mathrm{pH}$. Other parameters such as density, viscosity, torque percent, and spreadability showed no significant difference ( $\mathrm{p} \leq 0.05$ ) with CG. Skin irritation test which was conducted on animals and humans showed no any adverse effects on skin. Microbiological test manifested that using methylparaben alone was sufficient to prevent the growth of microbes in the gel. The three veterinary radiologists found no significant difference $(\mathrm{p} \leq 0.05)$ between G1 and CG formulations. Stability study indicated that the gel was stable after storage at room temperature for 3 months.

Conclusion: The overall results suggest that the selected formula (G1) can be considered a successful ultrasound gel and can be used as a good and cheap alternative of the marketed imported gel.

Keywords: Carbopol 934, Gel, Transmission test, Ultrasonography,

(C) 2019 The Authors. Published by Innovare Academic Sciences Pvt Ltd. This is an open access article under the CC BY license (http://creativecommons. org/licenses/by/4. 0/) DOI: http://dx.doi.org/10.22159/ajpcr.2019.v12i1.30150

\section{INTRODUCTION}

Ultrasound waves have been used as a medical diagnostic to image the human body for over half a century. Ultrasound can be defined as wavelengths that exceed the upper limit for audible human hearing, that is, $>20 \mathrm{kHz}$. Ultrasound devices in medical fields use sound waves in the range of $1-20 \mathrm{MHz}$ [1].

In recent years, ultrasound transmission gel (USTG) became commonly used as a conductive medium in many diagnostic procedures such as electrocardiography, ultrasonography, endoscopy, and transesophageal echocardiogram examinations [2].

The USTG does not only squish the air from between the probe and the skin but it also provides lubrication for movement. Ultrasound gel is manufactured as both sterile and non-sterile preparations. It is also used during transesophageal echocardiogram examinations [3].

Unfortunately, some chemicals used for the preparation of USTG are allergenic to skin, such as phenoxyethanol, methylisothiazolinone, and isothiazolinones which are used as preservatives for many industrial and cosmetic products and there are many publications dealing with patients who have developed allergic dermatitis as a result of using these chemicals in the formulation of the gel [4-6].

The USP defines gels as semisolids, either suspension of small inorganic particles or large organic molecules interpenetrated throughout the liquid. Gels are transparent or translucent semisolid formulations containing a high ratio of solvent/gelling agent $[7,8]$.
Carbomers are synthetic high molecular mass polymers of acrylic acid cross-linked with alkenyl ethers of sugars or polyalcohols. Depending on the degree of cross-linking and manufacturing conditions, different grades of carbomers are available in market such as Carbopol (CAR) 934, CAR 940, and CAR 981 [9-11].

Carbomers swell in water up to 1000 times their original volume to form a gel when exposed to a pH environment between 4.0 and 6.0. Accordingly, a neutralizing agent is applied to jellify CAR particles in many liquids or mixtures of liquid with water $[12,13]$. The monomer unit of carbomer is shown in Fig. 1.

Carbomer gels have been applied in producing gels, creams, lotions, and as drug vehicles in several administration routes $[11,13]$.

Propylene glycol (1,2-propanediol) has become widely used as a solvent or cosolvent, humectant, and preservative in a variety of pharmaceutical formulations. It is generally regarded as a relatively nontoxic, noncorrosive material. It is also used extensively in foods and cosmetics $[10,14]$.

This study aims to prepare a good quality ultrasound gel using the available chemicals in Iraqi market and without causing any harmful effects to skin. The objectives include the formulation of an optimized CAR-based ultrasound gel; then the formulation will be evaluated and compared with the commercial ultrasound gel by several tests.

\section{MATERIALS AND METHODS}

Materials

CAR 934 was purchased from HIMEDIA, India, propylene glycol was purchased from THOMAS BAKER, India, methylparaben was 
purchased from Direvo, Germany, triethanolamine was obtained from Tedia, USA, and blue dye (Basic blue 8, C.I. number 42563) was purchased from local market. All other chemicals were of analytical grade.

\section{Methods}

\section{Preparation of gel formulations}

Several gel formulations containing four different concentrations of the polymer CAR $934(0.3 \%, 0.4 \%, 0.5 \%$, and $0.6 \%)$ with other ingredients (Table 1) were prepared. During preparation procedure, accurately weighed amount of methylparaben was added to $1 / 3$ the volume of distilled water in a beaker. The measured amount of propylene glycol was added to the beaker which was kept under stirring using magnetic stirrer with heating at about $70-80^{\circ} \mathrm{C}$ until dissolving all methylparaben, then $0.1 \%$ blue dye solution was added. After that, accurately weighed amount of CAR 934 powder was sprinkled gradually to the previous mixture with continues stirring keeping the temperature at about 70$80^{\circ} \mathrm{C}$ using heat jacket technique. The final dispersion was left overnight at room temperature for complete swelling of the polymer. In the next day, $\mathrm{pH}$ was adjusted to 5-5.5 with the addition of a sufficient quantity of triethanolamine at room temperature with continuous mixing to attain the final gel formulation $[15,16]$. The finally prepared USTG is shown in Fig. 2.

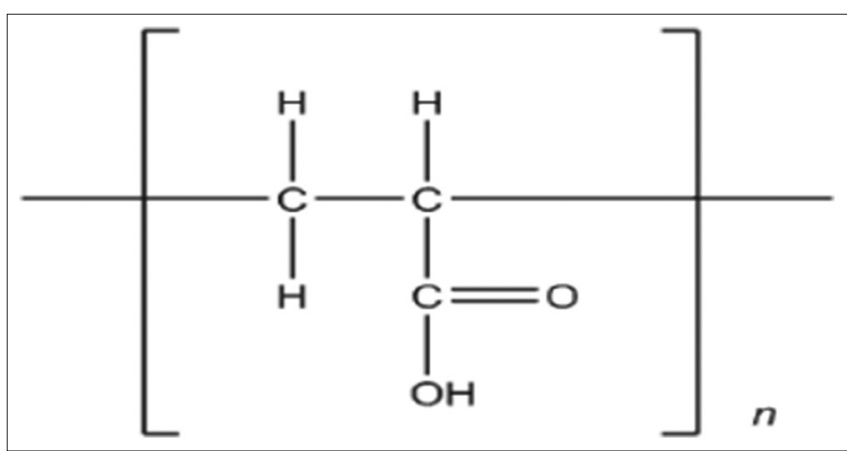

Fig. 1: A structural formula of acrylic acid monomer unit in carbomer polymer [10]

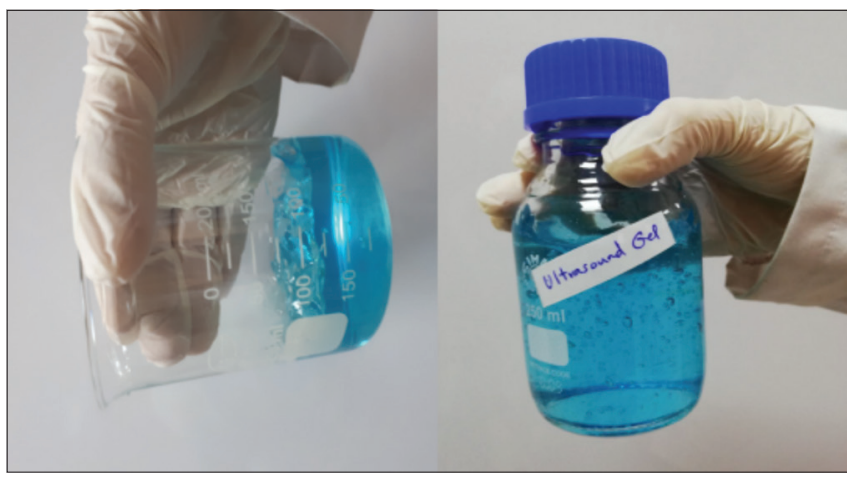

Fig. 2: The prepared ultrasound transmission gel
Evaluation of the prepared USTG

Physicochemical tests

Evaluation by physicochemical tests was performed by comparing results of the prepared USTG with those of the commercially available ultrasound gel (Aquasonic 100, Parker, Italy) which was considered as the control (commercial gel [CG]), these tests include the following:

Visual clarity and appearance

All prepared USTG formulations were inspected visually for their clarity, appearance, color, and consistency against a black and white background $[17,18]$

\section{Homogeneity}

All prepared USTG formulations were characterized for homogeneity assessment. This was done by visual inspection of the gel after the settlement of gel in suitable beakers. Gels were observed for their appearance, existence of any aggregate, type of smear, after feel, and how is the removal of gel $[9,19]$

Density measurement

Density can be measured by pycnometer, which is a glass flask with a close-fitting glass stopper with a capillary hole through it. It is basically used to measure the density of any homogenous object according to USP30-NF25, so it can be used to measure the density of homogenous gels. A scrupulously clean, dry pycnometer was calibrated by measuring its weight. Then, it was filled with each gel formulations (G1, G2, G3, and G4) and weighed again after removing any excess of the gel using filter paper. The density of gel that was filling the pycnometer can be calculated according to equation (1),

$\rho=\frac{m}{v}$

Where $\rho$ is the density $(\mathrm{g} / \mathrm{ml}), \mathrm{m}$ is the mass of gel alone $(\mathrm{g})$, and $\mathrm{v}$ is the volume of pycnometer (ml) [20].

\section{$\mathrm{pH}$ determination}

About $2.5 \mathrm{~g}$ of the gel was weighed and dissolved in $25 \mathrm{ml}$ of distilled water, and the $\mathrm{pH}$ was measured after $2 \mathrm{~h}$. The $\mathrm{pH}$ of all prepared USTG and (CG) was measured using a digital pH meter [17,21]

\section{Viscosity measurements}

Brookfield viscometer (model D 220, USA) was used to measure the viscosity and torque of all formulations (G1, G2, G3, and G4) in addition to the CG at $23 \pm 2{ }^{\circ} \mathrm{C}$ using spindle (T-Bar, TD-94). Sample holder of the Brookfield viscometer was filled with the gel sample, and then spindle was inserted into this holder. The spindle was rotated at $20 \mathrm{rpm}$. Viscosity and Torque measurements were recorded in triplicate $[9,22]$

\section{Spreadability test}

Spreadability was determined for all USTG formulations and the (CG) using a home-made apparatus. This apparatus consists of a wooden block, which was provided by a pulley at one end. By this method, two glass slides of the same dimensions were used, and spreadability was calculated on the basis of "slip" and "drag" characteristics of the gels. A ground glass slide was fixed on the wooden block. An excess of gel (about $2 \mathrm{~g}$ ) under study was placed on the surface of the ground slide.

Table 1: Composition of USTG formulations

\begin{tabular}{|c|c|c|c|c|c|c|}
\hline \multirow[t]{2}{*}{ Formulation code } & \multirow[t]{2}{*}{ CAR $934(w / v) \%$} & \multirow{2}{*}{$\begin{array}{l}\text { Propylene glycol } \\
\text { (w/v)\% }\end{array}$} & \multirow{2}{*}{$\begin{array}{l}\text { Methylparaben } \\
(w / v) \%\end{array}$} & \multirow{2}{*}{$\begin{array}{l}\text { Triethanolamine } \\
\text { (ml) }\end{array}$} & \multirow{2}{*}{$\begin{array}{l}\text { Blue dye } 0.1 \% \\
(\mathrm{ml})\end{array}$} & \multirow[t]{2}{*}{ D.W. } \\
\hline & & & & & & \\
\hline G1 & 0.3 & 5 & 0.05 & 0.2 & 0.15 & q.s \\
\hline G2 & 0.4 & 5 & 0.05 & 0.2 & 0.15 & q.s \\
\hline G3 & 0.5 & 5 & 0.05 & 0.2 & 0.15 & q.s \\
\hline G4 & 0.6 & 5 & 0.05 & 0.2 & 0.15 & q.s \\
\hline
\end{tabular}

USTG: Ultrasound transmission gel, CAR 934: Carbopol 934 
The gel was then sandwiched between this slide and an upper glass slide which was provided with a hook. A weight of $100 \mathrm{~g}$ was placed on the top of the two slides for nearly $5 \mathrm{~min}$ to expel air and to provide a uniform thin film of the gel between the two slides. Excess of the gel was removed from the edges. The upper glass plate was then subjected to a pull of $20 \mathrm{~g}$ weight with the help of a string attached to the hook and the time (in seconds) required by the upper slide to travel a distance of $7.5 \mathrm{~cm}$ was noted. A shorter interval indicates better spreadability. Spreadability (S) was calculated through the following equation:

$$
\mathrm{S}=\mathrm{M} \cdot \mathrm{L} / \mathrm{T}
$$

Where $\mathrm{S}$ = spreadability, $\mathrm{M}$ = weight tied to upper slide (g), $\mathrm{L}=$ length of glass slide $(\mathrm{cm})$, and $\mathrm{T}=$ time taken by the slide to travel the distance (sec) $[23,24]$.

\section{Skin irritation test}

Skin irritation test was performed for all the prepared formulations of USTG and CG on human volunteers to find out any irritation problems which could make it unsuitable for use. Three human volunteers were selected to check skin irritancy test. Only $1 \mathrm{~g}$ of the gel was topically applied to the hand over a 2 square inch. In this test, the three human volunteers signed an informed consent letter for their agreement to participate. Observation for any lesions, irritation, edema, or redness was performed at regular intervals for about $24 \mathrm{~h}$ and recorded $[22,25]$.

\section{Selection of USTG formulation}

According to the above tests, the appropriate formula was selected and used for further evaluations to ensure its acceptance as the best formula.

Evaluation by microbiological test for the selected USTG formulation

In this test, nutrient agar media were used. Two formulations of the selected USTG were prepared, the first one with methylparaben, which named $\left(\mathrm{G}^{\mathrm{p}}\right)$, the other contains no methylparaben $\left(\mathrm{G}^{\circ}\right)$ which is a blank gel. A small sample of each formulation was placed in a $5-\mathrm{ml}$ beaker which is then introduced into an autoclave $\left(15 \mathrm{mmHg}, 121^{\circ} \mathrm{C}\right)$ for $15 \mathrm{~min}$. Then, samples of each $\left(\mathrm{G}^{\mathrm{p}}\right)$ and $\left(\mathrm{G}^{\circ}\right)$ were exposed to air at room temperature and in the refrigerator for half an hour, and then aseptically inoculated in nutrient agar. Plates were incubated at $37 \pm 2^{\circ} \mathrm{C}$ for about $48 \mathrm{~h}$. The growth of microbial was checked continuously up to 2 days [26].

Evaluation by transmission test and comparative study for the selected USTG formulation

This study was initiated and mainly conducted at Veterinary Educational Hospital, College of Veterinary Medicine at University of Mosul during September 2018. 11 adult local cattle breed aged 3-8 years were examined by three veterinary radiologists at standing position; liver was imaged from the $12^{\text {th }}$ intercostal space at the right side. $70 \%$ alcohol was sprayed on the skin as disinfectant then two types of ultrasound gel were used (CG and the selected USTG). Each animal was examined twice, first using CG then after $15 \mathrm{~min}$; the examined area was cleaned and re-examined by the selected USTG. A curved transducer $3.5-5 \mathrm{MHz}$ and ultrasonographic machine (kx5100vet) were used (KeeboMed, USA) [27]. Datasheets for transmission information as shown in Fig. 3 were given to the radiologists to collect data, the collected data were assessed on whether the image was adequate through a simple yes/no question for each examination and also on image details, resolution, and quality through the use of three separate $0-10$ scoring scales $[4,28]$.

\section{Stability study for the selected USTG formulation}

The selected USTG formulation was tested for stability which was performed at $25 \pm 2^{\circ} \mathrm{C}$ for 3 months. A well-closed container was used for the storage of optimized USTG at $25 \pm 2^{\circ} \mathrm{C}$. Samples were observed at an aforethought time interval of 30 days, 60 days, and 90 days. At the end of 3 months, the selected formula was evaluated for its physical properties including appearance, color, presence of clogs or aggregates, consistency, viscosity, density, and spreadability. The selected formula was also evaluated for chemical parameters like change in $\mathrm{pH}[29,30]$

\section{Statistical analysis}

The results were given as mean \pm standard deviation and statistically analyzed using a t-test, $\mathrm{p}<0.05$ was considered as significant. Proportions of images deemed to be of adequate quality, by each type of gel used, were reported. Mean values for image quality, resolution, and detail based on 1-10 scales were also reported.

\begin{tabular}{|c|c|c|c|c|c|c|c|c|c|c|}
\hline \multirow{2}{*}{$\begin{array}{l}\text { Cow no.: } \\
\text { Weight: }\end{array}$} & & \multicolumn{6}{|c|}{ Age: } & \multicolumn{3}{|c|}{ Gender: } \\
\hline & \multicolumn{10}{|c|}{ Commercial (control) gel } \\
\hline Parameter & 1 & 2 & 3 & 4 & 5 & 6 & 7 & 8 & 9 & 10 \\
\hline \multicolumn{11}{|l|}{ Image details } \\
\hline \multicolumn{11}{|l|}{ resolution } \\
\hline quality & & & & & & & & & & \\
\hline \multicolumn{5}{|c|}{ Adequacy } & \multicolumn{6}{|c|}{ yes } \\
\hline
\end{tabular}

\section{Selected ultrasound gel}

\begin{tabular}{|l|c|c|c|c|c|c|c|c|c|c|}
\hline Parameter & $\mathbf{1}$ & $\mathbf{2}$ & $\mathbf{3}$ & $\mathbf{4}$ & $\mathbf{5}$ & $\mathbf{6}$ & $\mathbf{7}$ & $\mathbf{8}$ & $\mathbf{9}$ & $\mathbf{1 0}$ \\
\hline Image details & & & & & & & & & & \\
\hline resolution & & & & & & & & & & \\
\hline quality & & & & & & & \multicolumn{7}{|c|}{ yes } \\
\hline
\end{tabular}

Fig. 3: Datasheet given to the veterinary radiologists for data collection 


\section{RESULTS AND DISCUSSION}

\section{Evaluation by physicochemical tests}

Visual clarity and appearance

Clarity is one of the most important characteristic features of ultrasound gels. All formulations were of high clarity, transparent, with blue color, smooth homogeneous texture, and glossy appearance. Results are presented in Table 2.

\section{Homogeneity}

All developed USTG formulations were tested for homogeneity by visual inspection after the gels have been set in the beakers (Table 2).

\section{Density measurement}

Measurement of density using pycnometer was carried out for all prepared USTG formulations as well as for (CG). Filling the pycnometer was so difficult because of the high viscosity of formulations G1, G2, and CG. Furthermore, it was inapplicable for G3 and G4 formulations. Results of G1, G2, and CG (Table 3) showed that the densities of these formulations were near water density; this is mainly attributed to their high aqueous content.

\section{$\mathrm{pH}$ determination}

$\mathrm{pH}$ is one of the most important parameters involved in topical gel formulations due to the three areas of critical importance which are as follows: The effect of $\mathrm{pH}$ on solubility, the effect of $\mathrm{pH}$ on stability, and the effect of $\mathrm{pH}$ on skin well-being. The $\mathrm{pH}$ of any ultrasound gel formulations should be such to ensure formulation stability and at the same time to cause no irritation to the patient on administration of the formulation. Ultrasound gel formulations should have a $\mathrm{pH}$ ranging between 5 and 7.4. The pH of various gel formulations (G1, G2, G3, and G4) were determined using digital $\mathrm{pH}$ meter. The measurement of $\mathrm{pH}$ of each formulation was carried out in triplicate, and the average values are represented (Table 3).

\section{Viscosity determination}

The viscosity of a gel is a measure of its resistance to flow, and any gel formulation consistency depends mainly on its viscosity. Results of viscosity determination (Table 4) indicated that when the concentration of CAR 934 increased, this will lead to an increase in viscosity. The lower the viscosity was in G1 which has the lower CAR 934 concentration and vice versa and in agreement with USP30-NF25; the viscosity of a neutralized $0.5 \%$ aqueous dispersion of CAR 934 gel (G3) was in the range of $30,500-39,400$ centipoises [20,31]. However, there is a significant $(\mathrm{p}<0.05)$ change in viscosity between G1 and the CG which can be overcome using $<0.3 \%$ CAR 943 concentration in future work.

\section{Spreadability test}

All formulations showed good spreadability when applied between the two glass slides as shown in Table 4. A shorter interval of time in seconds that was required to travel the distance of $7.5 \mathrm{~cm}$ indicated the excellent spreadability of the gel. It was clear that the spreadability of G1 was highly similar to the spreadability of CG.

\section{Skin irritation test}

After performing this test and observation for any harmful effect at regular intervals for about $24 \mathrm{~h}$, results showed that there were no redness, irritation, edema, or any other side effect at any time interval after application, as shown in Table 5.

\section{Selection of USTG formulation}

The appropriate formulation of USTG was reviewed in terms of clarity, appearance, homogeneity, density, $\mathrm{pH}$, viscosity, spreadability, and skin irritation test. Among all formulations of USTG; the selected one was G1 which contains $0.3 \%$ (w/v) CAR 934. This formulation showed high clarity, very good appearance, blue color, smooth consistency, no phase separation, good after feel, no greasy, easy to
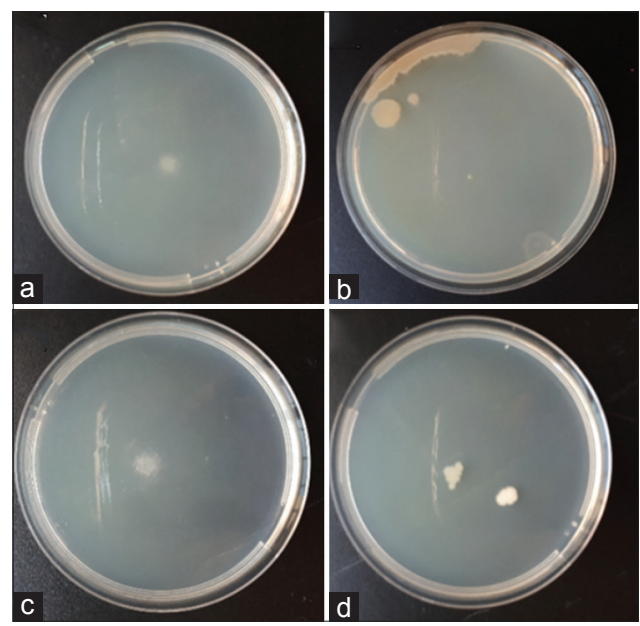

Fig. 4: Microbial growth in nutrient agar plates after incubation at $37 \pm 2^{\circ} \mathrm{C}$ for 2 days. Plates $\mathrm{A}$ and $\mathrm{C}$ represent ultrasound transmission gel (USTG) with methylparaben, Plates B and D represent USTG with no methylparaben
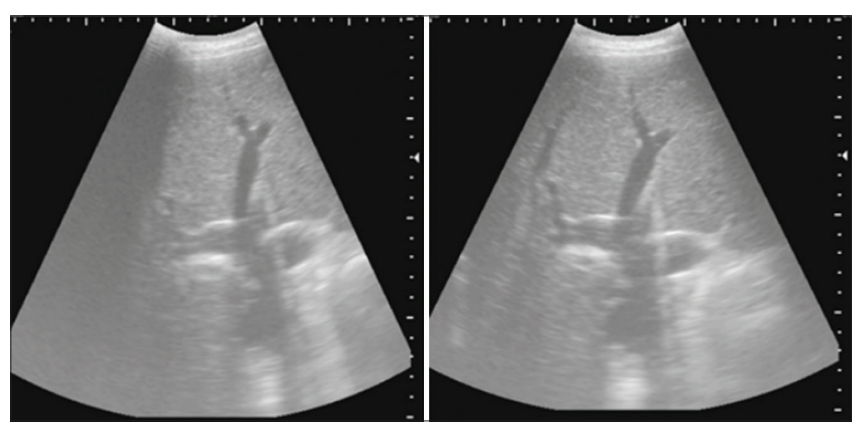

Fig. 5: Ultrasonogram of bovine liver imaged from the $11^{\text {th }}$ intercostals space of the fourth animal. The left one was performed using commercial gel, the right one was performed using the selected, prepared gel formulation (G1)

Table 2: Physical characteristics of the prepared USTG (G1, G2, G3, and G4) and the CG formulations

\begin{tabular}{|c|c|c|c|c|c|}
\hline Parameter & G1 & G2 & G3 & G4 & CG \\
\hline Clarity & High & High & High & High & Very high \\
\hline Appearance & Very good & Good & Good & Good & Very good \\
\hline Color & Blue & Blue & Blue & Blue & Blue \\
\hline Consistency & Smooth & Smooth & Smooth & Smooth & Smooth \\
\hline Phase separation & None & None & None & None & None \\
\hline Homogeneity & Very good & Good & Good & Moderate & Very good \\
\hline After feel & Good & Good & Good & Good & Good \\
\hline Type of smear & Nongreasy & Nongreasy & Nongreasy & Nongreasy & Nongreasy \\
\hline Removal & Easy & Easy & Easy & Easy & Easy \\
\hline
\end{tabular}

USTG: Ultrasound transmission gel, CG: Commercial gel 
remove from skin, and no skin irritation. Moreover, G1 gave results of density, viscosity, $\mathrm{pH}$, and spreadability very similar to those of CG. For the above reasons, G1 was selected as the most appropriate USTG formulation.

Table 3: Density and pH of the prepared USTG (G1, G2, G3, and G4) and the CG formulations

\begin{tabular}{llllll}
\hline Parameter & G1 & G2 & G3 & G4 & CG \\
\hline Density $\left(\mathrm{g} / \mathrm{cm}^{3}\right)$ & 0.996 & 0.997 & Inapplicable & Inapplicable & 0.983 \\
pH & 6.55 & 6.24 & 5.60 & 5.28 & 7.48 \\
\hline
\end{tabular}

Mean \pm SD, $n=3$. SD: Standard deviation, CG: Commercial gel, USTG: Ultrasound transmission gel

Table 4: Viscosity, torque, and spreadability of the prepared USTG and the CG formulations

\begin{tabular}{llllll}
\hline Parameter & G1 & G2 & G3 & G4 & CG \\
\hline Viscosity (cp) & 26400 & 30000 & 34500 & 35800 & 14600 \\
Torque (\%) & 26.1 & 30.0 & 34.5 & 35.8 & $14.6 \%$ \\
Spreadability (g.cm/s) & 8.67 & 8.23 & 6.20 & 4.43 & 8.60 \\
\hline
\end{tabular}

Mean \pm SD, $n=3$. SD: Standard deviation, CG: Commercial gel, USTG: Ultrasound transmission gel

Table 5: Type of harmful effect of the prepared USTG and the CG formulations

\begin{tabular}{llll}
\hline Formulation & Redness & Irritation & Edema \\
\hline G1 & NIL & NIL & NIL \\
G2 & NIL & NIL & NIL \\
G3 & NIL & NIL & NIL \\
G4 & NIL & NIL & NIL \\
CG & NIL & NIL & NIL \\
\hline
\end{tabular}

Mean \pm SD, $n=3$. SD: Standard deviation, CG: Commercial gel, USTG: Ultrasound transmission gel
Evaluation by microbiological test for the selected USTG formulation

By doing this simple test, it was easy to demonstrate the effectiveness of using methylparaben alone as a preservative of the formulation in two conditions. Nutrient agar media were used, where two formulations of the G1 were incubated. Fig. 4 shows the microbiological test; Plates A and $\mathrm{C}$ represent $\mathrm{G}^{\mathrm{p}}$ (with methylparaben) at room temperature and at refrigerator, respectively, results showed no microbial growth for all interval of times up to 2 days; while Plates B and D represent $\mathrm{G}^{\circ}$ (no methylparaben) showed apparent growth of bacilli in both conditions, but keeping $\mathrm{G}^{\mathrm{p}}$ in refrigerator may diminish microbial growth as in Plate D.

Evaluation by transmission test and comparative study for the selected USTG formulation

Liver was selected by the veterinary radiologists as the key organ for examination; the bovine liver is situated near the right body wall; its cranial aspect is hidden by the lung. 22 ultrasonographic scanning was performed for the 11 standing animals and 33 datasheets shown in Fig. 4 were given to each one of the three veterinary radiologists to collect results. All veterinary radiologists found the prepared gel equal and even superior to the (CG) during application and scanning. Results demonstrated that there was no statistical difference $(\mathrm{p}<0.05)$ between CG and the selected prepared gel (G1) in terms of image details, resolution and quality, as well as the adequacy. A summary of results is shown in Table 6. The prepared (G1) formula was found to be superior to commercially available gel (CG) with respect to image scores (Table 6). The mean image-details scores were 6.08 for G1 formula versus 5.65 for the commercially available gels (CG) $(\mathrm{p} \leq 0.05)$. The mean image resolution scores were 6.45 for G1 formula versus 5.76 for $C G$ formula $(p \leq 0.05)$. The mean image quality scores were 6.88 versus 6.33 for CG $(p \leq 0.05)$. Although the mean adequacy proportion of CG was found to be superior to G1, the difference is not statistically significant $(\mathrm{p} \leq 0.05)$. The ultrasonograms were taken for all of the 11 examined animals; the fourth one is presented in Fig. 5 as a sample.

Table 6: Ultrasound transmission test and comparative study between the prepared (G1) and the CG formulations using eleven adult local cattle breed aged 3-8 years

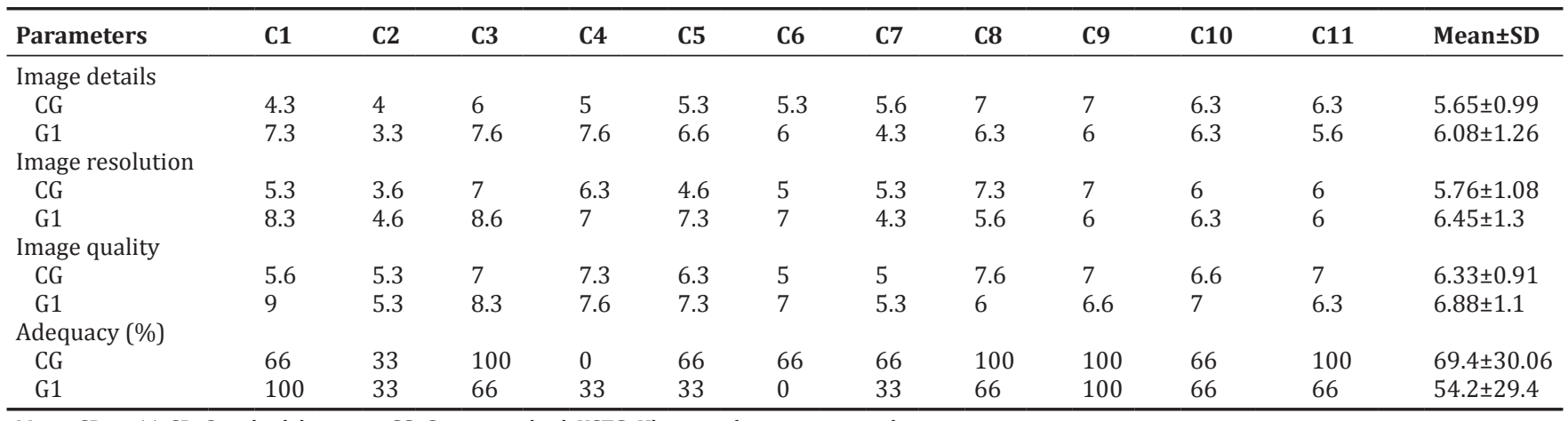

Mean \pm SD, n=11. SD: Standard deviation, CG: Commercial gel, USTG: Ultrasound transmission gel

Table 7: Physical properties of the selected (G1) after storage at room temperature for 3 months

\begin{tabular}{lll}
\hline Properties & Before storage & After storage \\
\hline Visual appearance and homogeneity & High clarity and very good homogeneity & High clarity and very good homogeneity \\
Density (g/cm ${ }^{3}$ ) & 0.996 & 0.995 \\
pH & 6.55 & 6.9 \\
Spreadability (g.cm/s) & 8.67 & 11.35 \\
Viscosity (cp) & 26400 & 26200 \\
Torque (\%) & 26.1 & $26.27 \%$ \\
Skin irritation test & Nil & Nil \\
Transmission test & Very good & Very good \\
\hline
\end{tabular}

Mean \pm SD, $n=3$. SD: Standard deviation, CG: Commercial gel, USTG: Ultrasound transmission gel 


\section{Stability study for the selected USTG formulation}

When the prepared (G1) was kept tightly closed and stored at room temperature for 3 months, no difference in visual appearance and homogeneity was observed. In addition, there was no significant difference $(\mathrm{p}<0.05)$ within density, $\mathrm{pH}$, spreadability, viscosity, and transmission tests after the period of the study (Table 7). The results concluded a successful and simple method to formulate an alternative USTG that is of good quality, free from allergenic chemicals and of the lower cost if compared with the available marketed ultrasound gel. Formula G1 containing $(0.3 \%)$ CAR 934, propylene glycol, methylparaben, and triethanolamine showed great similarity with CG in all evaluation tests except viscosity which was higher than that of CG. For this reason, a lower concentration of CAR 934 may be recommended to get lower viscosity. The overall results lay the groundwork for additional research that can be used to power larger trials for scale-up of the new alternative ultrasound gel.

\section{ACKNOWLEDGMENTS}

We are grateful to all whom gave us support and help in doing this work. Zena Al-Nima, assistant professor, College of Pharmacy, University of Baghdad. Our thanks and appreciations also go to our colleagues at College of Pharmacy, University of Mosul: Dr. Marwah H. Dawood, lecturer, Department Clinical Laboratory Science and both of Mohammed Khalid Al-Shaheen and Rasha Khalid Shakir, Assistant lecturers, Department Pharmaceutics, for their help in performing important tests in this study.

\section{AUTHORS' CONTRIBUTIONS}

All the authors have contributed equally.

\section{CONFLICTS OF INTEREST}

Declared none.

\section{REFERENCES}

1. Atlas of Ultrasound-Guided Procedures in Interventional Pain. Narouze SN, editor. Toronto, Canada: Springer Science Business Media, LLC; 2011.

2. Basic Physics. WHO Manual of Diagnostic Ultrasound. $2^{\text {nd }}$ ed. Geneva, Switzerland: World Health Organization Press; 2011. p. 3-4.

3. O'Rourke M, Levan P, Khan T. Current use of ultrasound transmission gel for transesophageal echocardiogram examinations: A survey of cardiothoracic anesthesiology fellowship directors. J Cardiothorac Vasc Anesth 2014:28:1208-10.

4. Binkowski A, Riguzzi C, Price D, Fahimi J. Evaluation of a cornstarchbased ultrasound gel alternative for low-resource settings. J Emerg Med 2014;47:e5-9.

5. Garcia-Miguel J, Lamas-Doménech N, Barceló-Garcia P. Allergic contact dermatitis in medical professionals due to exposure to ultrasound gel. Reumatol Clin 2016;12:115-6.

6. Chasset F, Soria A, Moguelet P, Mathian A, Auger Y, Francès C, et al. Contact dermatitis due to ultrasound gel: A case report and published work review. J Dermatol 2016;43:318-20

7. Sekar M, Ali A, Subramanian GS, Manoharan VS, Jason JI, Yean PA. Formulation and evaluation of natural ultrasound gel for physiotherapy treatment. Indo Am J Pharm Sci 2017:4:2548-54.

8. Nanda S, Saroha K, Sharma B. Formulation, evaluation and optimization of transdermal gel of ketorolac tromethamine using face centered central composite design. Int J Pharm Pharm Sci 2014;6:133-9.

9. Helal DA, El-Rhman DA, Abdel-Halim SA, El Nabarawi MA. Formulation and evaluation of fluconazole topicl gel. Int J Pharm
Pharm Sci 2012;4 Suppl 5:176-83

10. Rowe RC, Sheskey PJ, Quinn ME. Handbook of Pharmaceutical Excipients. $6^{\text {th }}$ ed. UK, USA: Pharmaceutical Press; 2009.

11. Kaur D, Raina A, Singh N. Formulation and evaluation of carbopol 940 based glibenclamide transdermal gel. Int J Pharm Pharm Sci 2014;6:434-40.

12. Lee JS, Song KW. Rheological characterization of carbopol 940 in steady shear and start-up flow fields. Annu Trans Nord Rheol Soc 2011; 19: 609-753.

13. Desai DD, Schmucker JF, Light D. CarbopolUltrez 10 Polymer: A New Universal Thickener fort the Personal Care Industry. Clevelend: Noveon, the Lubrizol Corporation; 2006.

14. Gaikwad VL, Yadav VD, Dhavale RP, Choudhari PB, Jadhav SD. Effect of carbopol 934 and 940 on fluconazole release from topical gel formulation: A factorial approach. CPR 2012;2:487-93

15. Gardouh AR, Ghorab M, Badawy S, Gales RB. Preparation and characterization of mucoadhesive buccal film for delivery of meloxicam. Br J Pharm Res 2013;3:743-66.

16. Esmaeel ST. Formulation and Evaluation of Nystatin Microspheres as a Topical Dosage Form MSc Thesis. Pharmacy Collage, University of Mosul; 2017. p. 40-6.

17. Patil S, Kadam A, Bandgar S. Formulation and evaluation of an in situ gel for ocular drug delivery of anti conjunctival drug. Cellulose Chem Technol 2015;49:35-40.

18. Prasanthi D, Lakshmi PK. Optimisation of transdermal gel formulations of tolterodine tartrate by experimental design. Turk J Pharm Sci 2013;10:273-86

19. Nawaz A, Jan SU, Khan NR, Hussain A, Khan GM. Formulation and in vitro evaluation of clotrimazole gel containing almond oil and tween 80 as penetration enhancer for topical application. Pak J Pharm Sci 2013;26:617-22.

20. United States Pharmacopeial Convention. USP 30 NF 25. $30^{\text {th }}$ ed. Mexico: United States Pharmacopeial Convention; 2007. p. 365-490.

21. Jadhav VD, Swati GT, Akshada AB, Chaudhari GN. Formulation and evaluation of herbal gel containing leaf extract of Tridax Procumbens. J Pharm BioSci 2015;3:65-72.

22. Shukr MH, Metwally GF. Evaluation of topical gel bases formulated with various essential oils for antibacterial activity against methicillinresistant Staphylococcus aureus trop. J Pharm Res 2013;12:877-84.

23. Hussain A, Khan GM, Shah SU, Shah KU, Rahim N, Wahab A, et al. Development of a novel ketoprofen transdermal patch: Effect of almond oil as penetration enhancers on in-vitro and ex-vivo penetration of ketoprofen through rabbit skin. Pak J Pharm Sci 2012;25:227-32.

24. Chakole CM, Shende MA, Khadatkar SN. Formulation and development of novel combined halobetasol propionate and fusidic acid ointment. Int J Chem Tech Res 2009;1:103-6.

25. Khullar R, Kumar D, Seth N, Saini S. Formulation and evaluation of mefenamic acid emulgel for topical delivery. Saudi Pharm J 2012;20:63-7.

26. Shende V, Telrandhe R. Formulation and evaluation of tooth gel from Aloe vera leaves extract. Int J Pharm Drug Anal 2017;5:394-8

27. Braun U. Ultrasonography of the liver in cattle. Vet Clin North Am Food Anim Pract 2009;25:591-609, Table of Contents.

28. Riguzzi C, Binkowski A, Butterfield M, Sani F, Teismann N, Fahimi J, et al. A randomised experiment comparing low-cost ultrasound gel alternative with commercial gel. Emerg Med J 2017;34:227-30

29. Chaudhary H, Rohilla A, Rathee P, Kumar V. Optimization and formulation design of carbopol loaded piroxicam gel using novel penetration enhancers. Int J Biol Macromol 2013;55:246-53.

30. Laxmi RJ, Karthikeyan R, Babu PS, Babu RV. Formulation and evaluation of antipsoriatic gel using natural excipients. J Acute Dis $2013 ; 1: 115-21$

31. Kim JU, Song JY, Park SK, Lee EJ. Rheological properties and microstructures of carbopol gel network system. Colloid Polym Sci 2003;281:614-23. 